\title{
Smallholder Rice Farmers' Adaptation Capacity to Climate Change in the Bawku Zone of Ghana
}

\author{
Abdul-Razak Zakaria and Kenichi Matsui
}

\begin{abstract}
This paper assesses smallholder rainfed rice farmers' adaptive capacity and strategies to climate change in the Upper East Region of Ghana. We conducted the questionnaire survey to understand how these farmers coped with climate change hazards. Most respondents reported to have used some adaptation strategies, such as using improved rice varieties, early planting, field bunding and rice transplanting. We also found that $68 \%$ of the respondents had medium adaptive capacity with seasonal and unsustainable alternative income sources. This finding at least partially explains why off-farm jobs in the area are not available and why $50 \%$ of the respondents had offered farm labor services as their alternative income source. We further demonstrate that smallholder rice farmers in the study area were vulnerable to several socio-economic challenges such as weak asset base and inadequate institutional and governmental support. These challenges threatened their ability to adapt to more intensive climate change impacts in the future.
\end{abstract}

Index Terms - Climate change adaptation, adaptive capacity, rice production, smallholder farmers, Ghana.

\section{INTRODUCTION}

Scholars have illustrated different types of adaptation among farmers. Smith et al. [1], for example, characterized three types of farmers' adaptation to climate change. One is physiological adjustment, which represents the natural capacity of a system to respond a climate hazard. The second type of adaptation is routine adjustment. Here farmers everyday consciously respond to climate variations (e.g., adjusting sowing time). The third type is tactical adjustment, in which farmers are required to change their behaviors (e.g., insurance subscription). Wreford et al. [2] distinguished private adaptation from public adaptation. The former engaged in some spontaneous or autonomous actions in response to market signals with or without government support. Niang et al. [3] similarly showed a disconnect in climate change adaptation actions in Africa where individual farmers undertook actions without government support.

Past studies on farmers' climate change adaptation also examined various strategies such as financial schemes,

Manuscript received October 9, 2019; revised March 15, 2020. This work received no financial support.

Abdul-Razak Zakaria is with the Graduate School of Life and Environmental Science, the University of Tsukuba, Japan (e-mail: s1930335@s.tsukuba.ac.jp).

Kenichi Matsui is with the Faculty of Life and Environmental Sciences, the University of Tsukuba, Japan (e-mail: kenichim@envr.tsukuba.ac.jp). technologies, religious and cultural customs, and communal support [4], [5]. One study examined how some American farmers changed planting time and adopted drought resistant crop varieties that were resistant to pest attack [6]. Similarly, in Ghana and many other African countries, farmers have diversified crop varieties, planted early maturing varieties, and changed crop types and planting time [7].

Although we have gained some general ideas about local adaptation strategies among farmers, other studies found that climate change adaptation actions varied partly due to socio-economic factors and geographical locations [8], [9]. Regional adaptation actions can be effective when adaptation policies better incorporate the adaptive capacity of a farmer or farming community [1], [10]-[12]. This paper, therefore, seeks to contribute to this area of scholarship by providing a case study on understudied climate vulnerable areas of Africa. In particular, we attempt to clarify the perceptions of smallholder rice farmers about climate change adaptation in the Upper East Region of Ghana. We set our research question as to what extent climate change adaptation studies can learn from practicing farmers. We argue that farmers have played and will play important roles in contributing to Ghana's regional climate change adaptation and food security.

In the following discussion, we clarify the significance of the Upper East Region. Then we explain how we conducted our field survey mainly by administering questionnaires among farmers. This is followed by our discussion of the survey results.

\section{StUdy AREA}

Climate change is already affecting Ghanaian livelihoods, especially rainfed agriculture in the Upper East Region. This region is in the savanna ecological zone with the mean annual rainfall of $1,000 \mathrm{~mm}$ and is characterized by extreme rainfall variability [13]. Climate projection models show that rainfall in this region will likely decline by about $80 \mathrm{~mm}$ per month in the future and further affect this region's food security [14]. An average farm size is estimated at 1.3 hectares with low average yield of $1.8 \mathrm{t} / \mathrm{ha}$ [15]. Climate change adaptation is essential for sustaining the livelihoods here.

\section{Methodology}

In order to assess farmers' adaptation capacity to climate change, we surveyed five districts in the Upper East Region: namely, Bawku East, Bawku West, Binduri, Garu-Tempane and Pusiga. These districts have similar characteristics in terms of the climate, soil type, farming system, culture, 
language and cultivated crops [16]. Due to its similar characteristics, these five districts are collectively known as the "Bawku zone." For sampling, we randomly selected three communities in each district and interviewed ten farmers in each community in their local language called kusaal. In total, we collected answers from 150 farmers. The Bawku zone possesses great potential in rice production because of its rich soils at the Basyonde, Binaba and Baring valleys, among others. It also has abundant labor [17].

We conducted this survey in July and August 2016. Prior to this survey, we conducted preliminary fieldwork to better design our questionnaire. We selected these months because by July farmers in these districts finish planting and weeding. For the survey, we first tried to understand socio-demographic characteristics of the respondents. Then the questionnaire asked about rice farmers' climate change adaptation strategies. We presented to the respondents with five strategies: early planting; using improved variety, contour bunding, seedling transplanting, and applying appropriate spacing. To assess their adaptation capacity, we used three different indicators: alternative livelihoods sources; community networks; and the institutional support. We then asked about the diversity of farmers' cash income sources. In categorizing the adaptive capacity of smallholder rice farmers to climate change hazards, we mainly examined their asset base (economic/financial assets). This was done within the context of sustainable livelihood approach. Past studies showed that a community or an individual with diversified income sources had a strong asset base and greater adaptive capacity [11], [18]. Farmers with more than five income sources were categorized as having high adaptive capacity; those with between four to five income sources had medium adaptive capacity; and those having between two to three income sources were categorized as having low adaptive capacity.

Abdul-Razak Zakaria, the lead author, has ten years of work experience as an extension service officer of the Department of Agriculture in Binduri district, which helped establish communication with local farmers. In analyzing the data, we used the Chi-Square test $\left(\chi^{2}\right)$ to clarify the relationship between respondents' socio-demographic characteristics and their climate change adaptation.

\section{RESUlTS AND DisCUSSION}

\section{A. Socio-demographic Characteristics of the Respondents}

Survey results show that $64 \%$ of the respondents were males. Regarding the age distribution, $87 \%$ of the respondents were between 20 and 59 years old. In particular, more than $60 \%$ was in their thirties or forties, showing good labor availability in the study area. Looking at their rice farming experience, about $70 \%$ had more than 10 years of experience, of which $40 \%$ had more than 20 years. Some even had more than 50 years of farming experience (Table I). As more than $80 \%$ of the respondents had not received formal education in the past, we can say that they had lived in the study area as farmers for most of their lives. Therefore, their observation and insights as farmers are largely reliable.
TABLE I: SOCIO-DEMOGRAPHIC CHARACTERISTICS OF THE RESPONDENTS

\begin{tabular}{lll}
\hline Social characteristics & Category & Frequency $(\%)$ \\
\hline Age & $20-29$ & $10(7 \%)$ \\
& $30-39$ & $33(22 \%)$ \\
& $40-49$ & $59(39 \%)$ \\
& $50-59$ & $28(19 \%)$ \\
& $60+$ & $20(13 \%)$ \\
Gender & Female & $54(36 \%)$ \\
Education & Male & $96(64 \%)$ \\
& Junior High School & $15(10 \%)$ \\
& Senior High School & $4(3 \%)$ \\
& Tertiary & $7(5 \%)$ \\
& Non-formal & $3(2 \%)$ \\
Years of experience & No education & $121(80 \%)$ \\
& & $47(31 \%)$ \\
& $11-20$ & $59(39 \%)$ \\
& $21-30$ & $30(20 \%)$ \\
& $31-40$ & $9(6 \%)$ \\
& $41-50$ & $4(3 \%)$ \\
& $51-60+$ & 150 \\
& &
\end{tabular}

\section{B. Farmers' Adaptation Strategies}

In the second part of the questionnaire survey, we asked the respondents about methods they had used to deal with changing climatic conditions. In particular, we identified five possible strategies for the respondents to choose (multiple choice). These strategies are appropriate spacing, contour bunding, rice transplanting, early planting, and planting early maturing variety. The result shows that $87 \%$ and $79 \%$ of the farmers began farming earlier and planted early maturing varieties, respectively. This means that drought conditions posed the highest challenge in the Bawku zone. In case of water shortage, contour bunds in the paddy fields help reduce water losses. About $71 \%$ of the respondents applied this method (Fig. 1). We also observed that most farmers relocated their farms to the Volta River Basin to take advantage of better soil and water conditions. Here farmers cultivate upland crops like maize, rice and sorghum after the first seasonal rain.

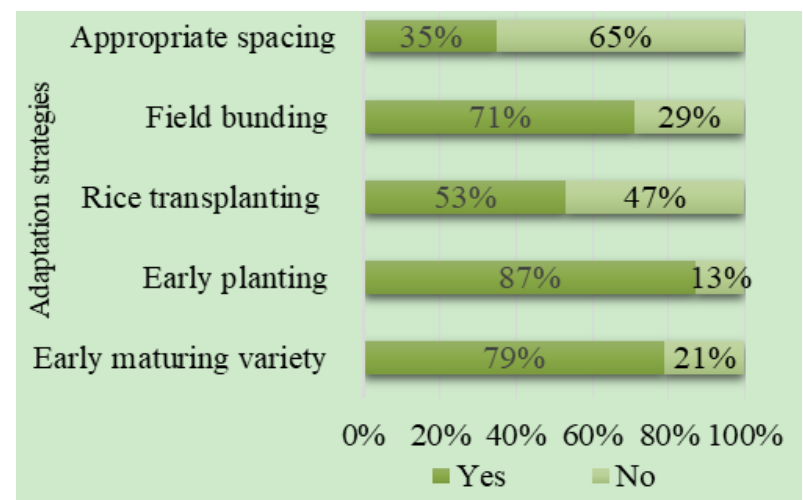

Fig. 1. Farmers' adaptation strategies. 
The Chi-Square test indicated that there was a significant difference in responses regarding the application of appropriate spacing within the age category $\left(\chi^{2}=11.901, \mathrm{df}=\right.$ 5 and $\mathrm{p}=0.018$ ) (Table III). Whereas $61 \%$ of the respondents in the 30-39-year age category applied appropriate spacing on their rice farms, only $30 \%$ of those in the $20-29$-year category did so (Table II). Generally young farmers in this area learn how to cultivate rice from their parents. They start farming in their twenties, and possibly still not finding and appreciating the importance of appropriate spacing in practice.

TABLE II: CHI-SQUARED (P-VALUE) ON SOCIO-DEMOGRAPHIC CHARACTERISTICS AND ADAPTATION STRATEGIES

\begin{tabular}{|c|c|c|c|c|c|}
\hline Socio-demographics & Early variety & Early planting & Transplanting seedlings & Contour bunding & Appropriate spacing \\
\hline \multirow[t]{2}{*}{ Age } & $2.57(0.63)$ & 0.84 & 6.59 & $1.05(0.90)$ & $11.90(* 0.02)$ \\
\hline & & $(0.93)$ & $(0.16)$ & & \\
\hline \multirow[t]{2}{*}{ Gender } & $1.42(0.23)$ & $0.36(0.55)$ & 1.37 & 0.65 & $2.11(0.15)$ \\
\hline & & & $(0.24)$ & $(0.42)$ & \\
\hline \multirow[t]{2}{*}{ Education } & $4.58(0.33)$ & $3.57(0.47)$ & 4.34 & 1.74 & $2.35(0.67)$ \\
\hline & & & $(0.36)$ & $(0.78)$ & \\
\hline \multirow[t]{2}{*}{ Experience } & 4.03 & $5.96(0.31)$ & 6.67 & $4.19(0.52)$ & 6.62 \\
\hline & $(0.54)$ & & $(0.25)$ & & $(0.25)$ \\
\hline
\end{tabular}

Note: Numbers in brackets show p-value

In answering the multiple-choice question about the effectiveness of adaptation strategies the respondents applied, $83 \%$ regarded early planting as effective. Also, $75 \%$ valued improved variety. Contour bunding (51\%) and transplanting rice $(37 \%)$ had mixed results. On the contrary, approximately $83 \%$ of the respondents perceived appropriate spacing as ineffective. This result shows that the respondents largely practiced customary open field sowing without much land engineering efforts. This is partly due to the severe weather for intensive labor work and lack of proper machineries for cultivating rice. Farmers do not usually have places to securely nurture rice seedings, either.

However, rice cultivation experts have advised that applying appropriate spacing is one of the major determining factors of improved rice yield and productivity. Applying appropriate plant spacing in rice farms determines plant productivity [19]-[21].

\section{Farmers' Adaptive Capacity}

In the third part of the questionnaire survey, we attempted to assess the level of adaptive capacity among the respondents. One of the ways to do so was to ask the respondents about their income sources. Diversifying income sources is particularly important for smallholder farmers to secure income. The result shows that $68 \%$ of the respondents had four to five income sources (Table III). In addition, 15\% of the respondents had more than five sources of income.

Their additional income sources included trading, remittance, labor services, firewood sale, fishing, sand wining and charcoal burning. These are usually seasonal in nature. In particular, the respondents relied on small ruminant rearing (47\%) and dry season gardening (38\%) as their alternative livelihood. Also, 53\% of the respondents offered labor services to other farmers. Farm labor pays less in this area than in other regions. The respondents further received support from food aid (42\%). However, 52\% said that they did not receive any support from government. Farmers in this area do not subscribe to crop insurance (Table III).

In most part of Ghana and other African countries, farmer-based organizations (FBOs) play important roles in improving farmers' adaptive capacity. These associations help farmers' access to credit facilities, farm inputs, extension services and other services at discount rates. Considering this situation, we asked the respondents if they belonged to FBOs for financial and in-kind support when they incurred crop loss due to climate hazards. The result shows that about half (48\%) of the respondents were members of farmer-based organizations (FBOs), whereas $27 \%$ belonged to Village Savings and Loans Associations (VSLAs), 15\% joined local cash deposit service group called susu (Table III).

\begin{tabular}{|c|c|c|}
\hline $\begin{array}{ll}\text { Adaptive } & \text { capacity } \\
\text { parameter } & \\
\end{array}$ & Capacity options & Responses (\%) \\
\hline \multirow{7}{*}{$\begin{array}{l}\text { Alternative livelihood } \\
\text { sources } \\
\text { (multiple choice) }\end{array}$} & Trading & $41(27 \%)$ \\
\hline & Remittance & $18(12 \%)$ \\
\hline & Offer labor services & $79(53 \%)$ \\
\hline & $\begin{array}{l}\text { Sell firewood or grass } \\
\text { for roofing }\end{array}$ & $16(11 \%)$ \\
\hline & Small ruminant rearing & $71(47 \%)$ \\
\hline & Shea nut picking & $18(12 \%)$ \\
\hline & Dry season gardening & $57(38 \%)$ \\
\hline \multirow{4}{*}{$\begin{array}{l}\text { Community networks } \\
\text { (multiple choice) }\end{array}$} & VSLAs & $41(27 \%)$ \\
\hline & FBOs & $72(48 \%)$ \\
\hline & Susu & $23(15 \%)$ \\
\hline & $\begin{array}{l}\text { Borrow (family and } \\
\text { friends) }\end{array}$ & $14(10 \%)$ \\
\hline \multirow{2}{*}{$\begin{array}{l}\text { Government } \\
\text { NGOs support }\end{array}$} & Food aid & $63(42 \%)$ \\
\hline & Grant from NGOs & $9(6 \%)$ \\
\hline
\end{tabular}




\begin{tabular}{rll}
\hline (multiple choice) & $\begin{array}{l}\text { No support from } \\
\text { government }\end{array}$ & $78(52 \%)$ \\
& Crop insurance & $0(0 \%)$ \\
Total & & $\mathbf{1 5 0}$ \\
\hline
\end{tabular}

In categorizing the adaptive capacity of smallholder rice farmers to climate change hazards, we mainly examined their asset base (economic/financial assets). This was done within the context of sustainable livelihood. A community or an individual with diversified income sources has a strong asset base and greater adaptive capacity [11], [18]. Farmer's income also determines their asset base. Our results revealed that only $15 \%$ fell under high adaptive capacity category. Majority of the respondents $(68 \%)$ were in medium adaptive capacity category. Their income sources included trading, remittance, labor services, selling firewood, fishing, sand wining and charcoal burning. These are usually seasonal in nature. Firewood selling and charcoal burning are unsustainable since they are not environmentally friendly. Moreover, $17 \%$ of the respondents had low adaptive capacity status (Table IV).

TABLE IV: ADAPTIVE CAPACITY CATEGORY OF RESPONDENTS

\begin{tabular}{|c|c|c|c|}
\hline Sources of income & Frequency (\%) & Category & \\
\hline & & $\begin{array}{l}2-3(\mathrm{~L}) \quad 4-5(\mathrm{M}) \\
(\mathrm{H})\end{array}$ & $>5$ \\
\hline $2-3$ & $25(17 \%)$ & Low (L) & \\
\hline $4-5$ & $102(68 \%)$ & Medium (M) & \\
\hline$>5$ & $23(15 \%)$ & $\operatorname{High}(\mathrm{H})$ & \\
\hline Total & 150 & & \\
\hline
\end{tabular}

\section{CONCLUSION}

This paper examined smallholder rice farmers' adaptation capacity by using the questionnaire survey. We argued that farmers contributed and will contribute to Ghana's regional climate change adaptation and food security. Local farmers without government support already dealt with drought by planting earlier and adopting early maturing varieties. As these farmers were more comfortable with maintaining customary rice practices, only a small portion of the respondents adopted land engineering, such as contour bunding and appropriate spacing. Partly due to a lack of nursery facilities, the respondents had not yet adopted rice transplanting. In order to enhance their survivability, the respondents were engaged in several works and external aid. About half of them offered their labor service to other farms and received mutual support from farmer-based organizations. Many respondents also raised small ruminants and engaged in dry season gardening. On the contrary, government support appears to be absent here.

Even though smallholder rice farmers in the Bawku zone have medium adaptive capacity, they diversified their livelihood sources and became connected to different social networks in order to access support to adapt to climate change hazards. This implies the application of multiple strategies in order to adapt to future climate change hazards. We argue that these experiences can help shape crop-specific climate change adaptation policy in the future. Also, climate change adaptation studies can pay more attention to the resilience and ingenuity of local farmers rather than treating them as climate change victims.

\section{CONFLICT OF INTEREST}

The authors declare no conflict of interest.

\section{AUTHOR CONTRIBUTIONS}

All authors designed the questionnaire; Abdul-Razak Zakaria conducted the research and analyzed the data; Abdul-Razak Zakaria and Kenichi Matsui wrote it; all authors approved the final version.

\section{ACKNOWLEDGMENT}

We are very grateful to all one hundred and fifty farmers and staff of the department of agriculture in the Binduri district of the Upper East region of Ghana who cooperated and helped us to gather data for this research.

\section{REFERENCES}

[1] J. B. Smith, N. Bhatti, G. Menzhulin, R. Benioff, M. Campos, B. Jallow, F. Rijsberman, M. I. Budyko, and R. K. Dixon, "Adapting to climate change: an international perspective," Springer Science \& Business Media, 2012, ch. 3, pp. 27-39.

[2] A. Wreford, D. Moran, and N. Adger, Climate Change and Agriculture: Impacts, Adaptation and Mitigation, OECD Publishing, 2010 .

[3] I. Niang, O. C. Ruppel, M. A. Abdrabo, A. Essel, C. Lennard, J. Padgham, and P. Urquhart, "Africa," in Climate Change 2014: Impacts, Adaptation, and Vulnerability, V. R. Barros, Ed. Cambridge, UK, and New York, USA: Cambridge University Press, 2014.

[4] N. Harmer and S. Rahman. "Climate change response at the farm level: A review of farmers' awareness and adaptation strategies in developing countries," Geography Compass, vol. 8, no. 11, pp. 808-822, 2014.

[5] J. Salick and A. Byg, "Indigenous peoples and climate change," Indigenous Peoples and Climate Change, Tyndall Centre Publication, 2007.

[6] B. A. McCarl, A. W. Thayer, and J. P. H. Jones. "The challenge of climate change adaptation for agriculture: An economically oriented review," Journal of Agricultural and Applied Economics. vol. 48, no. 4, pp. 321-344, 2016.

[7] B. Y. Fosu-Mensah, P. L. G. Vlek, and D. S. MacCarthy. "Farmers' perception and adaptation to climate change: A case study of Sekyedumase district in Ghana," Environment, Development and Sustainability, vol. 14, no. 4, pp. 495-505, 2012.

[8] T. C. Kumasi, P. Antwi-Agyei, and K. Obiri-Danso, "Small-holder farmers' climate change adaptation practices in the Upper East Region of Ghana," Environment, Development and Sustainability, vol. 21, no. 2, pp. 745-762, 2017.

[9] F. Ndamani and T. Watanabe, "Determinants of farmers' adaptation to climate change: A micro level analysis in Ghana," Scientia Agricola, vol. 73, no. 3, pp. 201-208, 2016.

[10] M. S. Allahyari, S. Ghavami, and Z. D. Masuleh. "Understanding farmers' perceptions and adaptations to precipitation and temperature variability: Evidence from Northern Iran," Climate, vol. 4, pp. 4-58, 2016.

[11] P. J. M. Cooper, J. Dimes, K. P. C. Rao, B. Shapiro, B. Shiferaw, and S Twomlow. "Coping better with current climatic variability in the rain-fed farming systems of sub-Saharan Africa: An essential first step in adapting to future climate change?" Agriculture, Ecosystems \& Environment, vol. 126, no. 1-2, pp. 24-35, 2008.

[12] G. A. Gbetibouo, "Understanding farmers' perceptions and adaptations to climate change and variability: The case of the Limpopo Basin, South Africa," IFPRI Discussion Paper 849, International Food Policy Research Institute (IFPRI), 2009. 
[13] Ghana Statistical Service. (2012). 2010 Population and Housing Census. Ghana Statistical Service. [Online]. pp. 1-117. Available: https://doi.org/10.1371/journal.pone.0104053

[14] P. Antwi-Agyei, "Vulnerability and adaptation of Ghana's food production systems and rural livelihoods to climate variability," $\mathrm{Ph} . \mathrm{D}$. dissertation, University of Leeds, 2012.

[15] G. Kranjac-Berisavljevic, R. M. Blench, and R. Chapman. (June 2003). Rice production and livelihoods in Ghana. [Online]. pp. 1-91. Available:

https://www.odi.org/projects/1114-multi-agency-partnerships-technic al-change-west-african-agriculture

[16] Ghana Statistical Service, District Analytical Report, Population and Housing Census, pp. 1-71, 2014.

[17] FARMD. (2014). Production risks and coping mechanisms: The case of rice farmers in the Upper East Region of Ghana. Seidu Al-Hassan Centre for Continuing Education and Interdisciplinary Research, University for Development Studies. [Online]. Available: (http://www.agriskmanagementforum.org/fstory/production-risk-rice)

[18] N. L. Engle. "Adaptive capacity and its assessment," Global Environmental Change, vol. 21, no. 2, pp. 647-656, 2011.

[19] A. W. Baloch, A. M. Soomro, M. A. Javed, M. Ahmed, H. R. Bughio, M. S. Bughio, and N. N. Mastoi. "Optimum plant density for high yield in rice (Oryza sativa L.)," Asian Journal of Plant Sciences, vol. 1, no. 1, pp. 25-27, 2002.

[20] S. Li, L. Juhász-Horváth, P. A. Harrison, L. Pintér, and M. D. A. Rounsevell, "Relating farmer's perceptions of climate change risk to adaptation behaviour in Hungary," Journal of Environmental Management, vol. 185, pp. 21-30, 2017.

[21] P. Reuben, F. C. Kahimba, Z. Katambara, H. F. Mahoo, W. Mbungu, F Mhenga, and M. Maugo. "Optimizing plant spacing under the systems of rice intensification (SRI)," Agricultural Sciences, vol. 7, no. 4, pp. 270-278, 2016.

Copyright $\odot 2020$ by the authors. This is an open access article distributed under the Creative Commons Attribution License which permits unrestricted use, distribution, and reproduction in any medium, provided the original

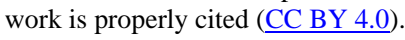

Abdul-Razak Zakaria is an agricultural extension officer in the Department of Agriculture at Binduri district of the Upper East Region of Ghana. He is currently pursuing the doctoral program in sustainable environmental studies at the University of Tsukuba, Japan. He holds a master's degree in environmental science from the University of Tsukuba, Japan. He also holds a bachelor of science degree in agriculture technology from the University for Development Studies, Ghana. His research interest areas are climate change, sustainable agriculture, value chain development, agribusiness and environmental policy.

Kenichi Matsui is an associate professor at the Faculty of Life and Environmental Sciences, the University of Tsukuba, Japan. 